\title{
ANALYSIS OF PCC MODEL DEPENDENT PERIODIC SIGNALS IN GLONASS POSITION TIME SERIES USING LOMB-SCARGLE PERIODOGRAM
}

\author{
Karol DAWIDOWICZ * and Grzegorz KRZAN
}

University of Warmia and Mazury in Olsztyn, Institute of Geodesy, Oczapowskiego 2, Olsztyn, Poland

*Corresponding author's e-mail: karol.dawidowicz@uwm.edu.pl

\begin{tabular}{l} 
ARTICLE INFO \\
\hline Article history: \\
Received 18 December 2015 \\
Accepted 11 April 2016 \\
Available online 28 April 2016 \\
\hline Keywords: \\
GLONASS \\
ASG-EUPOS \\
PCC \\
PCV \\
Receiver antenna phase center calibration
\end{tabular}

\section{INTRODUCTION}

The absolute elevation and azimuth-dependent phase center corrections (PCCs) obtained using anechoic chambers or a robot were introduced in November 2006 to replace pure elevation-dependent receiver antenna PCCs based on relative field calibrations (Wübenna et al., 1996; Rothacher, 2001; Görres et al., 2006). Currently, absolute PCCs are routinely used in both the International GNSS Service (IGS) and the EUREF Permanent Network (EPN) (Baire et al., 2011, 2013; Bruyninx et al., 2012). On the $17^{\text {th }}$ April 2011, the IGS and the EPN updated antenna calibration models from igs05.atx to igs08.atx. Rebischung et al. (2011) demonstrated with GPS-only solutions that the updated receiver antenna PCCs caused noticeable position offsets within the IGS network.

The absolute receiver antenna calibrations tables initially used within the IGS and EPN are means of the available individual robot calibrations for a specific antenna type. This type of calibration is indicated as antenna type-mean calibrations. This approach assumes that the PCCs of antennas of the same type can all be represented with sufficient accuracy by these type-mean calibrations.

In addition to the type-mean calibrations, currently the EPN uses the individual antenna calibrations, which refer to a specific antenna/radome type and antenna serial number. The antenna calibration file, which was used within the EPN, contains these individual antenna calibrations and also, for some antennas, the type-mean calibrations. So currently, one can distinguish between two types of absolute calibration tables: the individual calibration and the type-mean calibration. In the individual calibration one specific antenna is calibrated in several sets. Then different calibrations results from several sessions are combined to one unique file. In the type-mean calibration several antennas are calibrated in several sets. Then calibrations of several individual antennas of the same kind are combined to one unique file. For an antenna, where one has no individual calibration, the first approximation is a type-mean. If more accurate data 
are needed for this specific antenna, an individual calibration is recommended. The drawback of the type-mean is that the results are much noisier than for individual calibrations (Seeber et al., 1997; Menge et al., 1998; Rothacher, 2001; Schmid et al., 2005; Zeimetz and Kuhlman, 2008).

The antenna calibration for GLONASS signals differs in comparison to GPS because of the different frequencies of individual GLONASSS satellites. The robot estimated absolute phase center variations (PCV) for L1 and L2 are a mixture of observed GLONASS frequencies, visible during the time calibration. For this reason, the calibration results are satellite constellation dependent and are not as accurate as for GPS (Wübbena et al., 2006).

Nevertheless, the mixture of the observed GLONASS frequencies are used for calibration and this method allows frequency-dependent GLONASS PCV to be determined. The fundamental assumption of this concept is the linearity of PCV changes for GPS/GLONASS and GLONASS/GLONASS frequencies. This assumption is justified from the frequency ranges and is in accordance with the results from chamber calibrations (Schupler and Clark, 2001). In this approach the so-called Delta PCVs for the GLONASS signals are computed firstly based on the reference signals L1 and L2 from GPS (with the unit meter per 25.0 MHz). The Delta PCVs are then multiplied by the frequency difference between GLONASS and GPS and added to GPS PCVs. This procedure obtains GLONASS PCVs for any channel number $k$. A detailed description of this method can be found e.g. in (Wübbena et al., 2006). Alternatively, GPS PCC can be used for the correction of GLONASS PCV due to a lack of better information.

Most studies which concern the impact of PCC model on positioning are based on network solutions (e.g. Völksen, 2006; Khoda and Bruyninx, 2007; Chatazinikos et al., 2009; Dawidowicz, 2013; Dawidowicz et al., 2015). Recently, the Precise Point Positioning (PPP) technique has also been used in such analyzes. PPP is a stand-alone positioning technique using undifferenced dual-frequency code and phase observations (Kouba and Héroux, 2000; Shen, 2002; El-Mowafy, 2009). During the past decades, the development in the processing strategy for Global Navigation Satellite System measurements gave the possibility to obtain highly accurate satellite orbits, satellite clocks, and Earth rotation parameters (ERP). The International GNSS Service routinely generates these products, which are the basis for the development of Precise Point Positioning.

Differential GNSS (DGNSS) positioning methods require an access to the observations of one or more reference stations with known coordinates (Grinter and Roberts, 2011). The PPP technique has an advantage over differential methods in that only a single receiver is necessary (Zumberge et al., 1997; Geng et al., 2010; Rizos et al., 2012). In this technique, position is determined by means of a single GNSS receiver using undifferenced observations and measurement corrections. The corrections are derived from the GNSS data that are recorded at numerous global ground-based stations and employed to implement absolute and accurate positioning at only one single station without any synchronous GNSS observations from the base stations.

The advances in GNSS processing techniques in recent years as well as the improvement of the applied models have resulted in the significant reduction of background noise both in the satellite products and in station position time-series. These improvements motivated more detailed studies on geophysical processes. Continuous GNSS observations are permanently used in geodynamic studies. In such research, precise GNSS error modeling is very important. So far, the impact of switching from the type-mean to individual calibration model has been investigated e.g. in Baire et al. (2013), Sidorov and Teferle (2013). These studies have focused, however, on processing GPS-only observation.

To detect the periodicity in the authors' results the Lomb-Scargle spectrum was calculated. The Lomb-Scargle periodogram is an algorithm that specifically generates a Fourier spectrum for the instance where data are not uniformly spaced. As it is known, such situation occurs quite often in GNSS permanent observations. Unlike a traditional FFT, there is no zero frequency channel (Scargle, 1982; Townsend, 2010).

In the paper, the authors investigated the impact of the updated receiver antenna PCCs on eight selected ASG-EUPOS stations. In the analysis, the authors used GLONASS-only observations. They performed the post-processing using daily and subdaily (15 minutes) observations. The period covered one year of observations collected since December 2013 to November 2014 (daily post-processing). In pseudo-kinematic mode, the authors used data set gathered in December 2013. Some details of the observations are presented in the following section. The adjustment of data is based on the NAvigation Package for Earth Observation Satellites (NAPEOS) software (Springer, 2009) using PPP technique.

The analysis allows a better understanding of how receiver antenna calibration models contribute to GNSS positioning error budget and to GNSS position time-series.

\section{METHODOLOGY}

This study will focus on the effect of switching between PCC models on the station positions estimation. The authors used the type-mean calibration model, which can be considered the first approximation of PCC and the individual calibration model. The authors investigated how the deficiencies in the modeling of antenna phase centers variations contributed to the early mentioned periodic signals in GNSS position time-series. 


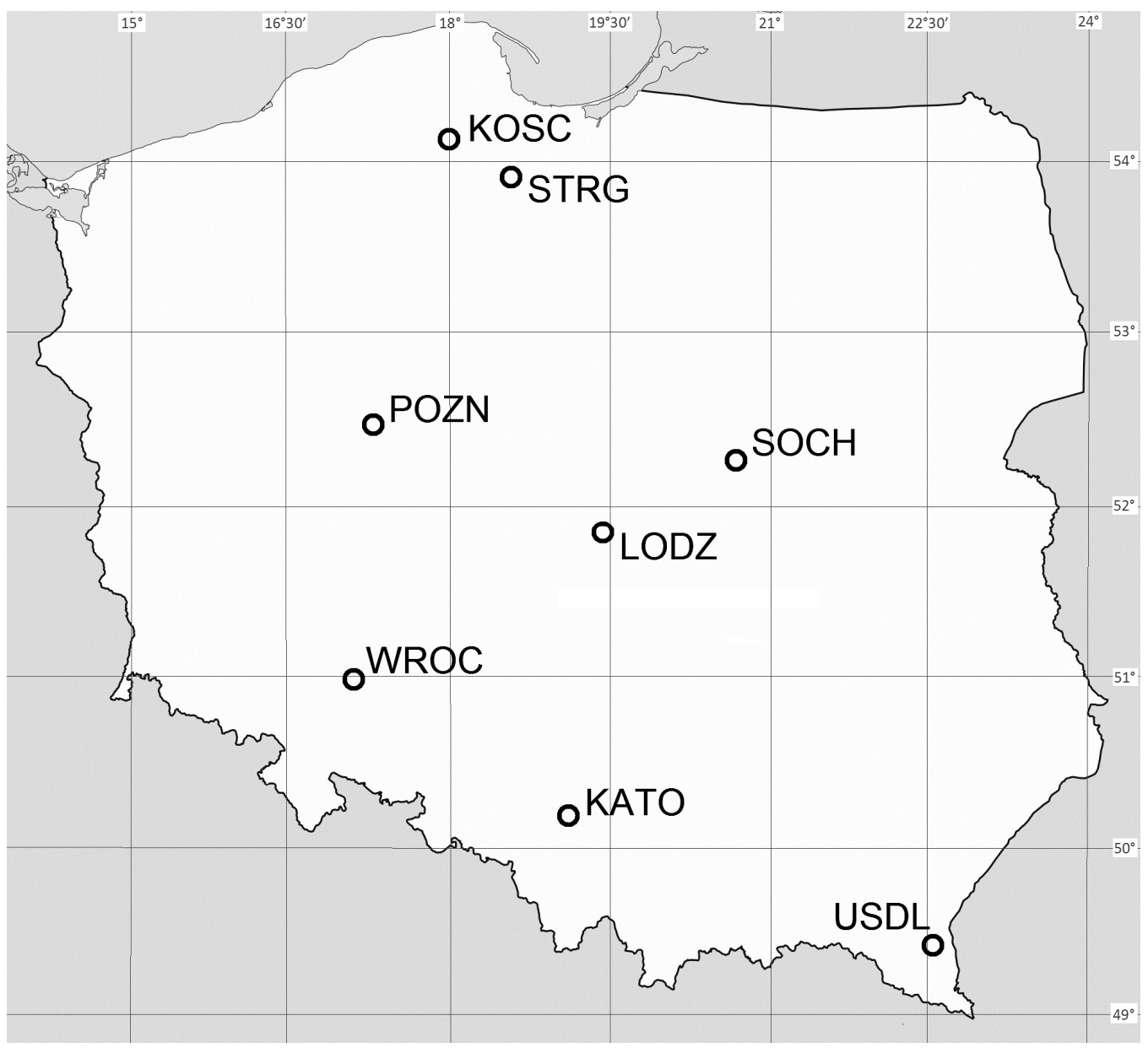

Fig. 1 Localization of the Polish GNSS stations chosen for analysis.

In the analysis, the authors used GLONASS observation from eight selected ASG-EUPOS station (Fig. 1). The ASG-EUPOS is the multifunctional precise satellite positioning system established by the Head Office of Geodesy and Cartography in 2008 (Bosy et al., 2005; Figurski et al., 2009, 2010; Kadaj, 2010; Bogusz et al., 2011). It consists of 49 Polish sites with GPS-only module, 53 Polish sites with GPS/GLONASS module and three foreign sites with GPS-only module and 20 foreign sites with GPS/GLONASS module (state for October 2015).

The current trend in EPN is to replace the type mean calibrations tables with the individual antenna calibrations, which refers to a specific antenna/radome type and antenna serial number. This trend is also visible in ASG-EUPOS network. Nowadays, (October 2015) 21 of 125 ASG-EUPOS stations are equipped with antenna having individual calibration (including 15 stations belonging to the EPN network). Currently, intense efforts aimed at introducing all antennas with individual calibration are performed.

In this study, the authors used individual calibrations from $\mathrm{Geo}^{++}$, University of Hannover (Institut für Erdmessung, IfE) and the state survey authorities of Berlin (SenStadt Berlin). Table 1 presents institutions providing PCC for antennas used in our investigation (Fig. 1).
Table 1 The calibration institutions providing PCC for used in test antennas.

\begin{tabular}{cccc}
\hline \multirow{2}{*}{$\begin{array}{c}\text { Calibration } \\
\text { type }\end{array}$} & \multicolumn{3}{c}{ Calibration institution } \\
\cline { 2 - 4 } & $\mathrm{Geo}++$ & IfE & SenStadt \\
\hline individual & $3 / 8$ & - & $5 / 8$ \\
type-mean & $7 / 8$ & $1 / 8$ & - \\
\hline
\end{tabular}

SenStadt uses the robot system developed by IfE and $\mathrm{Geo}^{++}$(Seeber et al., 1997; Seeber and Böder, 2002). In this study, the authors also used the typemean calibrations distributed by the IGS. The typemean values are provided to the IGS by calibration facilities (mostly by $\mathrm{Geo}^{++}$) together with information on the number of individual calibrations and the number of different antenna/ radome pairs used to compute the mean. The information is contained in ANTEX files (e.g. igs05.atx, igs08.atx)

On $17^{\text {th }}$ April 2011, the IGS adopted an IGSspecific realization of the ITRF2008, called IGS08, together with an updated antenna phase center model called igs08.atx. Major changes of igs08.atx with respect to igs05.atx were described in Schmid (2011). These include:

- satellite antenna $\mathrm{z}$-offsets from igs08.atx are consistent with IGS08, whereas those from 
Table 2 Characteristic of the points used in the analysis.

\begin{tabular}{ccccccc}
\hline \multirow{2}{*}{ No. } & \multirow{2}{*}{ Point } & \multirow{2}{*}{ Network } & \multicolumn{2}{c}{ Points hardware } & \multicolumn{2}{c}{ Calibration service } \\
\cline { 4 - 7 } & & & Antenna type & Receiver type & $\begin{array}{c}\text { Type- } \\
\text { mean }\end{array}$ & Individual \\
\hline 1 & LODZ & EPN/ASG-EUPOS & TRM55971.00 TZGD & TRIMBLE NETR5 & Geo++ & SenStadt \\
2 & USDL & EPN/ASG-EUPOS & TRM55971.00 TZGD & TRIMBLE NETR5 & Geo++ & SenStadt \\
3 & KATO & EPN/ASG-EUPOS & TRM57971.00 TZGD & TRIMBLE NETR5 & - & SenStadt \\
4 & SOCH & ASG-EUPOS & TRM57971.00 TZGD & TRIMBLE NETR5 & - & SenStadt \\
5 & KOSC & ASG-EUPOS & LEIAR20 LEIM & LEICA GR10 & Geo++ & Geo++ \\
6 & STRG & ASG-EUPOS & LEIAR20 LEIM & LEICA GR10 & Geo++ & Geo++ \\
7 & POZN & ASG-EUPOS & TRM59900.00 SCIS & TRIMBLE NETR9 & IfE & SenStadt \\
8 & WROC & EPN/ASG-EUPOS & LEIAR25.R4 LEIT & LEICA GR25 & Geo++ & Geo++ \\
\hline
\end{tabular}

igs05.atx were approximately consistent with IGS05,

- improved redundancy of satellite antenna $\mathrm{z}-$ offsets,

- preliminary block-specific $\mathrm{z}$-offsets for satellites launched since the release of igs05.atx replaced by satellite-specific estimates,

- $\quad$ increased maximum nadir angle for GLONASS satellite antenna phase center variations $\left(15^{\circ}\right.$ instead of $14^{\circ}$ ),

- availability of information on historical (GPS Block I and GLONASS) satellites,

- availability of GLONASS-specific receiver antenna corrections from robot calibrations,

- additional and updated robot calibrations,

- conversion of relative receiver antenna corrections with updated AOAD/M_T values.

The continuous GLONASS observations from eight Polish Ground-Based Augmentation Systems (ASG-EUPOS) with two different strategies were analyzed. Within the first one, $15 \mathrm{~min}$ observation windows were post-processing for investigation of the short-period oscillations (1 month of observation). The second was the daily solution using one year of observations. Table 2 contains some detailed information about the points used in this study.

The post-processing was done using the NAPEOS ver. 3.3.1. The authors performed two PPP runs, maintaining all processing options identical, except the antenna/radome calibrations model:

- a run using the type mean PCC (igs08.atx),

- a run using the individual PCC.

Finally, the differences between the results of these two post-processing were calculated. Because all error sources may be considered identical in both PPP runs, differences in the final solutions are only affected by variations in the antenna/radome calibrations. For the selected station and installed antenna/radome pair, the differences between the daily and sub-daily positions obtained using two PPP observations post-processing provide the position offset caused by the changed antenna calibration model.

As is well known PPP is characterized by the long convergence time (about 20 minutes or more) necessary for the ambiguity float solution. To be certain that the obtained differences, in our sub-daily analysis, are due to the change in antenna models, only converged solutions should be analyzed. To do this, The NAPEOS software was set up to not generate the results for the whole day if any of the $15 \mathrm{~min}$ session is divergent. Fortunately, there were no such cases for analyzed data, so we can be sure that there are no 'divergent solutions' in our results.

In the computations, a standard processing strategy was used with general weighted least squares parameter estimation method. First of all, the European Space Agency (ESA) precise orbit and clock information were applied. As data zerodifference GLONASS code and phase observations were used with $30 \mathrm{sec}$. sampling interval. Additionally $10^{\circ}$ elevation mask was adopted with elevation dependent weighting function $(1 / \cos (z))$. These parameters were selected because we try to compare station positions estimated using GLONASS-only observations when type-mean and individual calibration models were applied in typical postprocessing scenario. In this case, usually, elevation dependent weighting and $10^{\circ}$ elevation mask are used. A priori zenith path delays (ZPDs) were computed with formula of Saastamoinen (Saastamoinen, 1972) using Global Pressure and Temperature (GPT) model (Boehm et al., 2007); ZPDs were mapped into slant delays using hydrostatic Global Mapping Function (GMF) (Boehm et al., 2006). The a priori model was corrected during the parameter estimation. Estimation of zenith delay corrections will be made at 1-hour intervals for each station. The parameters were estimated in resolving the normal equations using the method of least squares (Springer, 2009; Leick et al., 2015). First-order Ionosphere effect was eliminated by forming ionosphere-free linear combination; higherorder effects were not corrected. The computations were based on the float ambiguity solution.

NAPEOS strictly follows the International Celestial Reference Frame (IERS) convention and 
Table 3 L1 offsets comparison.

\begin{tabular}{ccccccc}
\hline \multirow{2}{*}{ POINT } & \multicolumn{6}{c}{ Calibration dependent L1 offsets [mm] } \\
\cline { 2 - 7 } & \multicolumn{2}{c}{ North } & \multicolumn{3}{c}{ East } & \multicolumn{2}{c}{ Up } \\
\cline { 2 - 7 } & type-mean & individual & type-mean & individual & type-mean & individual \\
\hline LODZ & +1.13 & +1.16 & -0.17 & +0.16 & $\mathbf{+ 6 5 . 0 2}$ & $+\mathbf{6 7 . 0 2}$ \\
USDL & +1.13 & +1.24 & -0.17 & -0.12 & +65.02 & +65.99 \\
KATO & +1.11 & +1.00 & -0.32 & +0.06 & +66.77 & +66.82 \\
SOCH & +1.11 & +0.79 & -0.32 & +0.06 & +66.77 & +66.34 \\
KOSC & $+\mathbf{0 . 2 9}$ & $\mathbf{1 . 1 3}$ & -0.71 & -0.46 & $\mathbf{+ 1 2 6 . 7 4}$ & $+\mathbf{1 2 4 . 2 4}$ \\
STRG & +0.29 & +0.39 & -0.71 & -0.70 & $\mathbf{+ 1 2 6 . 7 4}$ & $+\mathbf{1 2 4 . 3 9}$ \\
POZN & +0.82 & +0.41 & $\mathbf{- 0 . 3 5}$ & $\mathbf{- 0 . 9 7}$ & +111.19 & +109.81 \\
WROC & $\mathbf{+ . 6 0}$ & $\mathbf{+ 1 . 2 6}$ & $\mathbf{+ 0 . 9 8}$ & $\mathbf{+ 0 . 1 9}$ & +158.30 & +158.51 \\
\hline
\end{tabular}

Table 4 L2 offsets comparison.

\begin{tabular}{|c|c|c|c|c|c|c|}
\hline \multirow[t]{3}{*}{ POINT } & \multicolumn{6}{|c|}{ Calibration dependent L2 offsets [mm] } \\
\hline & \multicolumn{2}{|c|}{ North } & \multicolumn{2}{|c|}{ East } & \multicolumn{2}{|c|}{ Up } \\
\hline & type-mean & individual & type-mean & individual & type-mean & individual \\
\hline LODZ & +0.23 & -1.12 & +0.84 & +0.25 & +57.43 & +59.16 \\
\hline USDL & +0.23 & +0.01 & +0.84 & +1.15 & +57.43 & +58.20 \\
\hline KATO & +0.07 & +0.18 & +0.66 & +1.08 & +57.79 & +57.21 \\
\hline $\mathrm{SOCH}$ & +0.07 & -0.58 & +0.66 & +1.00 & +57.79 & +57.31 \\
\hline KOSC & +0.07 & +0.62 & -0.66 & -0.09 & +135.20 & +130.80 \\
\hline STRG & +0.07 & +0.47 & -0.66 & -0.54 & +135.20 & +130.81 \\
\hline POZN & +0.38 & -0.08 & +0.48 & +0.28 & +124.76 & +121.29 \\
\hline WROC & +0.11 & +0.93 & +0.05 & -0.82 & +154.04 & +155.10 \\
\hline
\end{tabular}

used the IAU2000 transformation routines. Ocean loading values are obtained from the ocean loading service. Currently NAPEOS used the FES2004 with center of mass corrections (CMCs) (Scherneck, 1991; Blewitt, 2003). The tidal variations due to the Earth's rotations are fully implemented using the IERS subroutine (Springer, 2009).

In this study, GLONASS-only observations were processed and GLONASS specific PCC values were used to correct GLONASS observations.

Furthermore, it should be noted that so far there is no type-mean calibration results for TRM57971.00 TZGD antenna. In this case, the authors used typemean calibration results for TRM57971.00 NONE antenna as recommended.

At the start, however, the authors analyzed differences between type-mean and individual PCV for chosen stations. These comparisons were made independently for L1 and L2 frequency. The PCVs were converted to a common phase center offset (PCO), obtained via type-mean calibration and then differences between PCVs were calculated and displayed (Kersten and Schön, 2014).

\section{ANALYSIS OF ANTENNAS PCC DIFFERENCES}

The switch from type-mean (igs08.atx) to individual calibration tables was evaluated using eight selected Polish ASG-EUPOS stations. From the literature it is know that important height jumps have been reported at some continuously operating stations after installing the new GNSS receivers and antennas (Wanninger, 2011). These jumps may suggest that the absolute type-mean calibrations values, which are used today, are not optimal. To estimate the magnitude of inaccuracies in type-mean antenna calibration results the authors analyzed differences between type-mean and individual PCC for chosen stations.

In calibration results, the authors can distinguish:

- North, East, Up PCO for L1 and L2 frequency,

- Elevation-only dependent PCV (for L1 and L2 frequency),

- Elevation and azimuth dependent PCV (for L1 and L2 frequency).

Generally PCO and PCV values are necessary for the PCC calculation i.e., difference between the actual antenna phase centers of an individual measurement with respect to the antenna reference point (ARP).

Tables 3 and 4 present the offsets obtained using individual and type-mean (igs08.atx) calibration procedures.

The offsets differences were visible for the horizontal as well as for the up components. The horizontal (North, East) offsets differences are generally below $0.5 \mathrm{~mm}$. However, there were some exceptions: for North component at KOSC and 


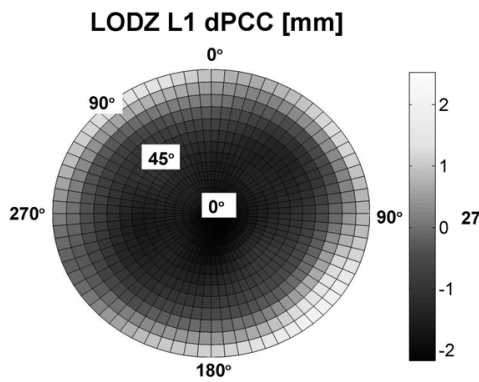

USDL L1 dPCC [mm]

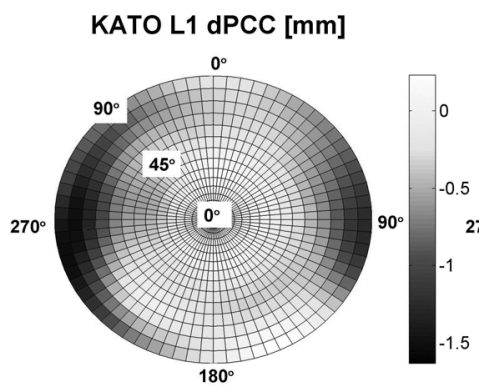

KOSC L1 dPCC [mm]
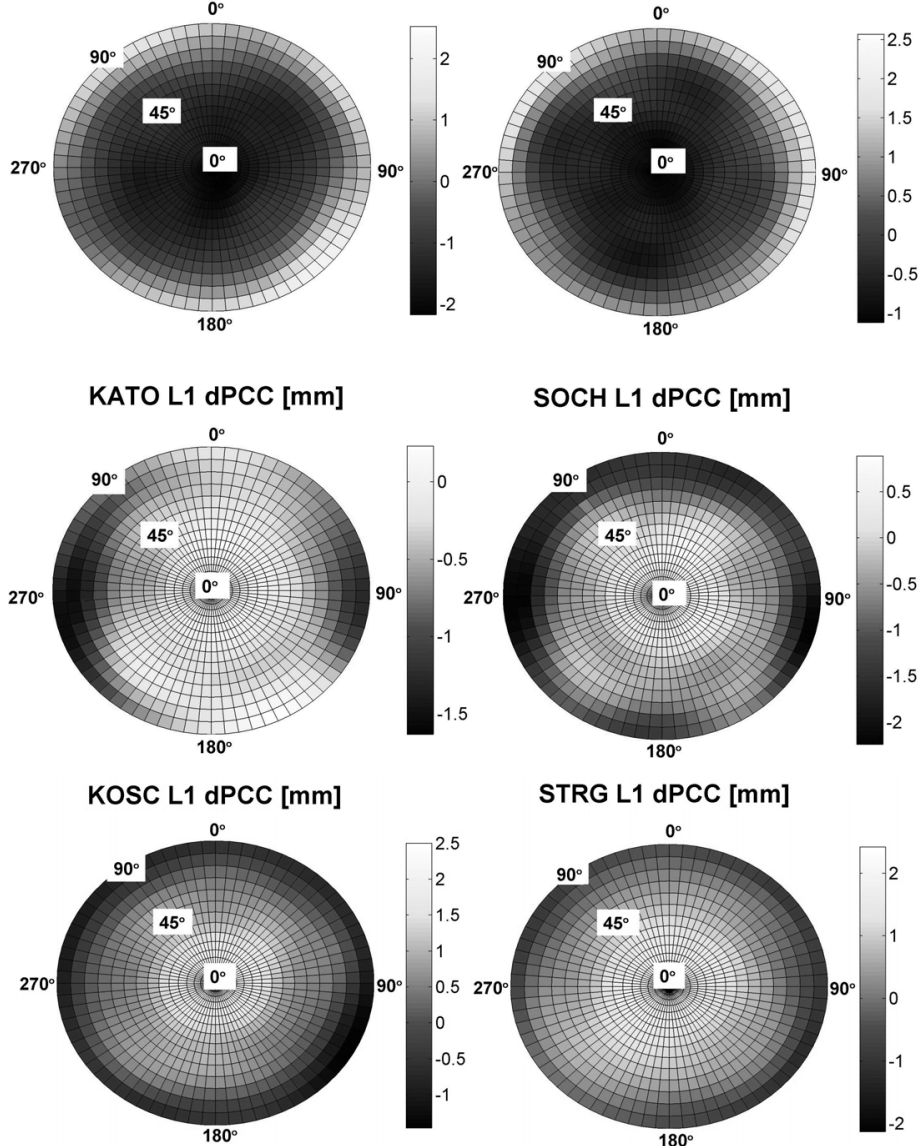

SOCH L1 dPCC [mm]

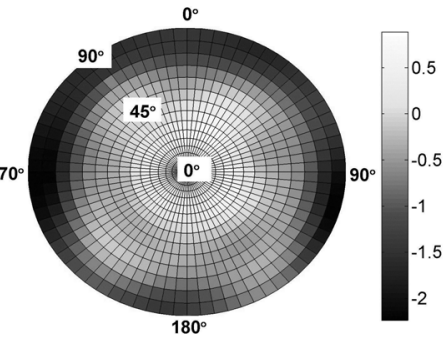

STRG L1 dPCC [mm]

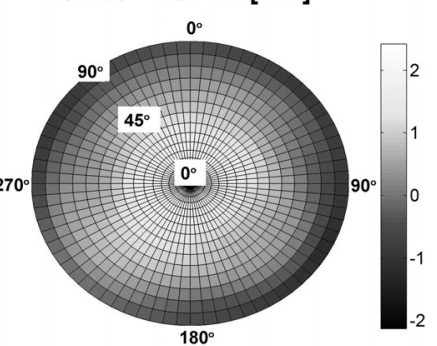

POZN L1 dPCC [mm]

WROC L1 dPCC [mm]
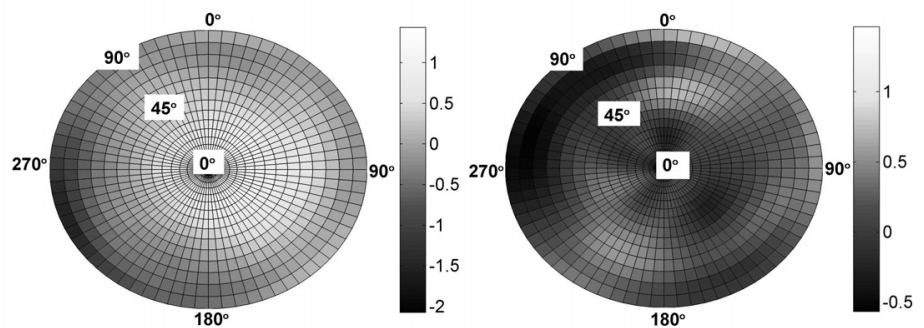

Fig. 2 GLONASS L1 frequency PCV differences between typemean and individual calibration.

WROC stations, for East component at POZN and WROC stations. For Up component the differences were significantly larger and for three stations (LODZ, KOSC, STRG) reach 2 or more millimeters.

While analyzing L2 frequency, it was observed that there were more stations where differences exceed $0.5 \mathrm{~mm}$. For North component four such stations were found and for East component - three. For Up component the maximum difference reached up to $5 \mathrm{~mm}$ (KOSC and STRG station - LEIAR20 LEIM antenna). There were also two stations (LODZ and POZN) where this difference reached $2 \mathrm{~mm}$.

The elevation dependent PCC was computed using elevation dependent spherical harmonic (expansion of degree 8 and order 0 ). The elevation dependent corrections are often applied in kinematic applications where the knowledge of the orientation of the antenna is unavailable. In the analysis, the authors used elevation and azimuth dependent PCC. Figures 2 and 3 present individual versus type-mean PCV differences.

Analyzing PCV differences for L1 frequency (Fig. 2), it can be observed that generally the influence of calibration type on calibration tables for selected for the test antennas has a magnitude of about 2-2.5 $\mathrm{mm}$ in low elevations. For higher elevation, obviously the differences decrease to zero. Additionally, it can be observed that for LEICA antennas (KOSC, STRG and POZN stations) differences are generally elevation dependent and for some TRIMBLE antennas (e.g. LODZ, USDL stations) differences are also strongly azimuth dependent. 

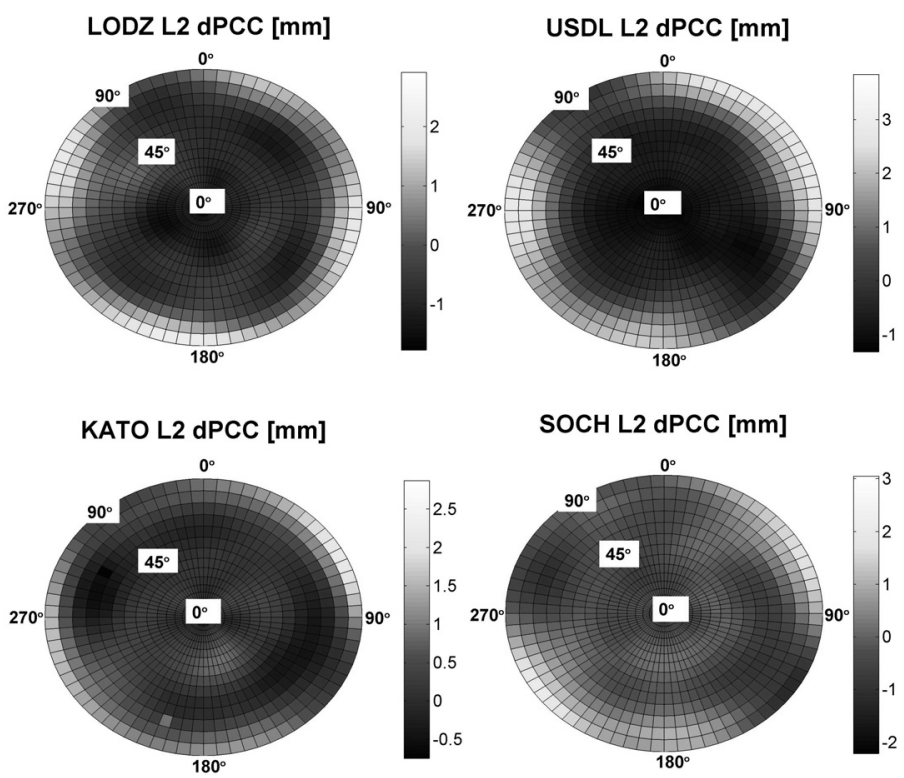

SOCH L2 dPCC [mm]
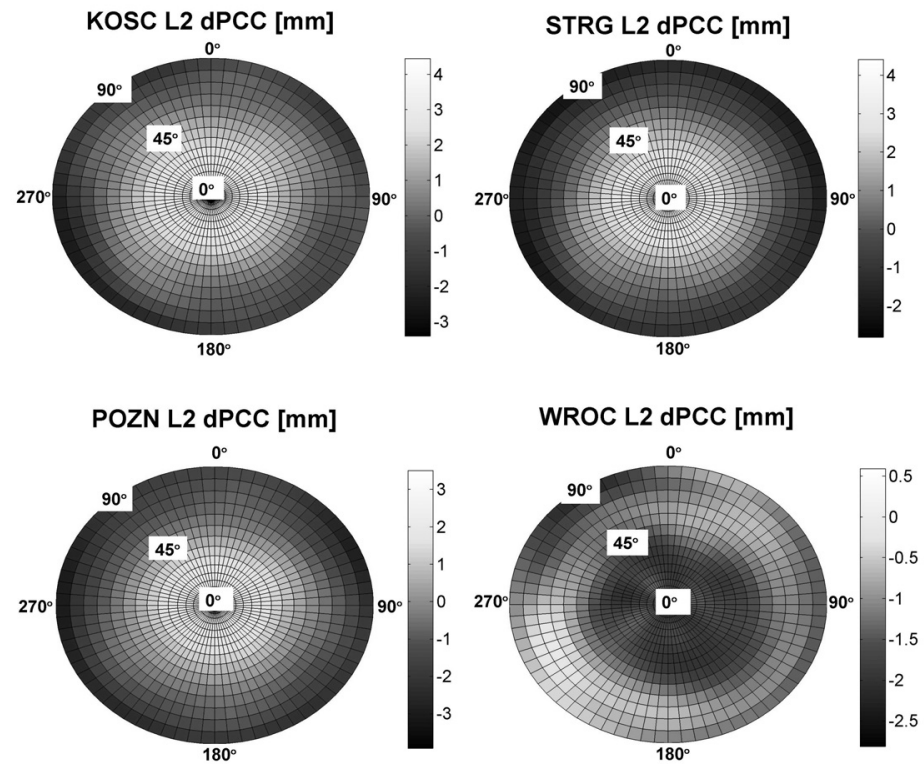

Fig. 3 GLONASS L2 frequency PCV differences between typemean and individual calibration.

Figure 3 presents PCV differences for L2 frequency. It was found that the influence of calibration type on calibration results is bigger for that frequency and reaches up to $3-4 \mathrm{~mm}$ in low elevations. As it was previously mentioned, it can be also observed that for LEICA antennas differences are generally elevation dependent and for TRIMBLE antennas differences are also strongly azimuth dependent.

Generally, for all antennas differences between type-mean and individual calibration tables were observed. These differences can be treated as inaccuracies in type-mean PCC. In the next section, the authors analyze how these differences influence the position time series.

\section{SUB-DAILY RESULT ANALYSIS}

The effect of switching from type-mean (igs08.atx) to individual calibration tables was evaluated using observation from eight selected Polish ASG-EUPOS stations. In sub-daily mode, the period covered one month of observations made in December 2013. Post-processing was done using the method described in "Methodology" section. In this section the authors analyzed the differences in North, East, Up components caused by switch from type-mean to individual calibration tables. Results are presented in Figure 4. For readability of the graphs, the results of only the first seven days are presented.

By analyzing the results presented in Figure 4, it is visible that the differences in all three position component have visible periodicity. The differences reveal the following: 

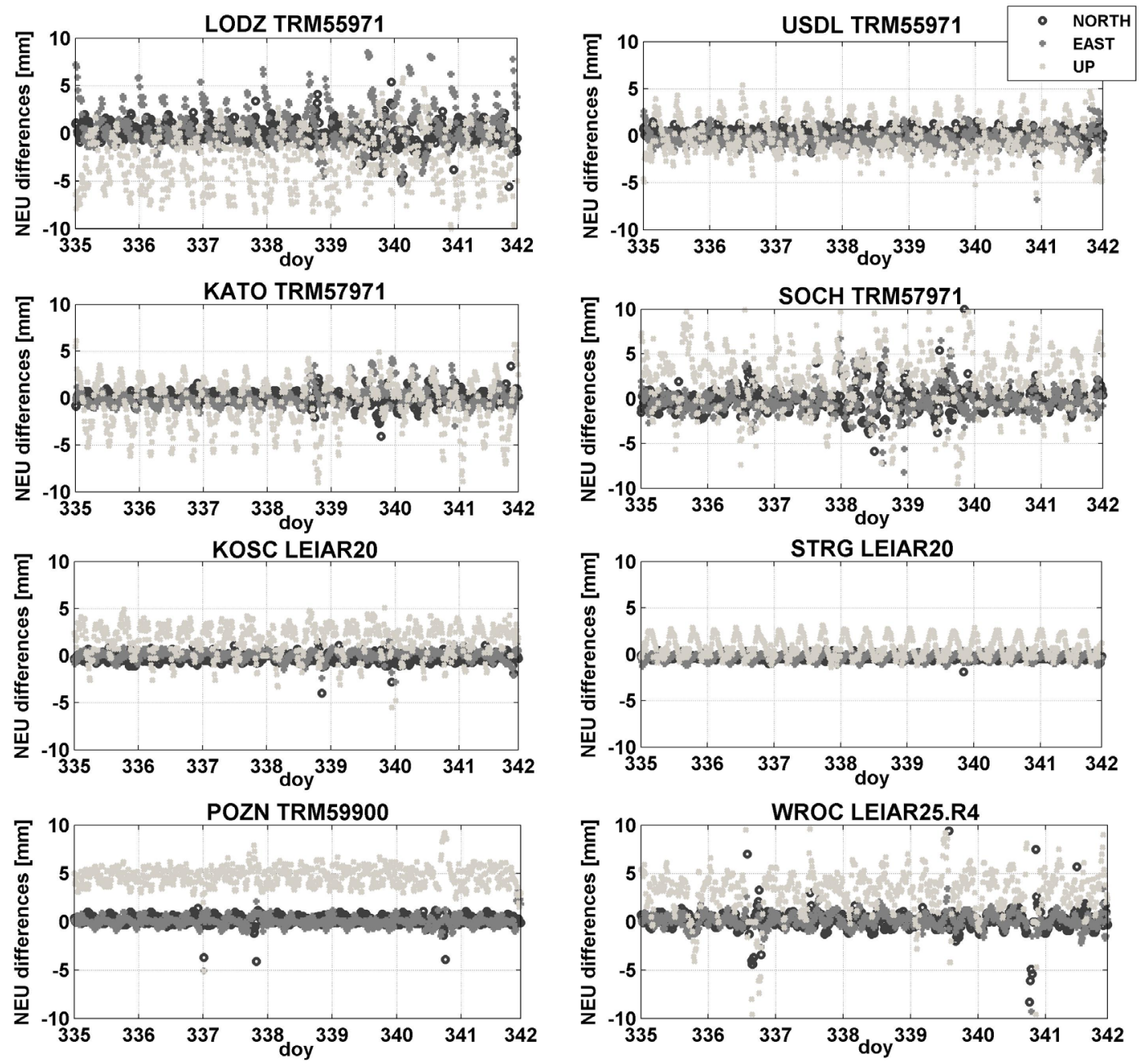

Fig. 4 North, East, Up differences caused by the use of different calibration models in sub-daily observation post-processing (the first seven days of December 2013).

- $\quad$ the presented stations exhibit periodic biases up to $10 \mathrm{~mm}$,

- $\quad$ differences experience rapid changes within short time periods,

- variations in differences have periods close to 8 hours.

For GPS signals, as the authors discovered in Sidorov and Teferle, 2013, these variations have periods about 12 hours, which agree with the orbital period of the GPS satellites. In the case of GLONASS satellites, the discovered periodicity does not correspond to the orbital period of the GLONASS satellites (11 hours 15 minutes). The three cycles per day period may be associated with three orbital planes in GLONASS. The strong $8 \mathrm{~h}$ periodicity in GLONASS position dilution of precision (PDOP) time series was found, e.g. in Meindl (2011), however calculated from incomplete GLONASS constellation.

The authors also observed that position offsets in the height component are clearly bigger than for horizontal components. For LODZ, KATO, SOCH, WROC stations (with TRIMBLE antenna, where PCC differences were clearly elevation and azimuth dependent) these offsets change up to $10 \mathrm{~mm}$.

By analyzing the results presented in Figure 4, it is visible also that at some sites (e.g. KOSC, POZN, WROC) the unexpected artifacts/outliers occurred. Detailed analysis of the observation files and postprocessing results show that, during the period of these incidental residuals, some gaps in data occurred. In our opinion, these gaps made more difficult the process of convergence the PPP solution which resulted in a lower precision of the solution. Furthermore, it is currently under investigation, that effects are able to move from one estimated parameter to the other. The parameters like troposphere, ambiguities or receiver clock estimates obtained from the interrupted sessions may have an incidental impact on the observed artifacts. These outliers were removed during the periodicity analysis.

Table 5 presents a summary of North, East, Up differences caused by the use of different calibration models in post-processing, i.e. maximum, minimum and average value of the obtained difference for all stations. 
Table 5 Summary of North, East, Up differences for sub-daily results.

\begin{tabular}{crrrrrrrrr}
\hline POINT & \multicolumn{3}{c}{$\begin{array}{c}\text { North component } \\
\text { differences }[\mathrm{mm}]\end{array}$} & \multicolumn{3}{c}{$\begin{array}{c}\text { East component } \\
\text { differences }[\mathrm{mm}]\end{array}$} & \multicolumn{2}{c}{ Up component differences [mm] } \\
& \multicolumn{1}{c}{ Max. } & \multicolumn{1}{c}{ Min. } & \multicolumn{1}{c}{ Average } & \multicolumn{1}{c}{ Max. } & \multicolumn{1}{c}{ Min. } & Average & Max. & Min. & Average \\
\hline LODZ & 12.5 & -5.6 & 0.0 & 14.6 & -5.3 & 0.8 & 5.8 & -16.7 & -2.9 \\
USDL & 1.6 & -17.5 & 0.2 & 2.9 & -6.8 & -0.4 & 9.7 & -10.8 & -0.2 \\
KATO & 3.4 & -4.1 & 0.0 & 4.2 & -3.0 & 0.0 & 6.1 & -9.0 & -0.7 \\
SOCH & $\mathbf{2 2 . 6}$ & $\mathbf{- 5 . 9}$ & -0.1 & 30.6 & -14.2 & -0.2 & $\mathbf{3 0 . 6}$ & $\mathbf{- 1 8 . 6}$ & 2.2 \\
KOSC & 1.4 & -4.0 & -0.2 & 1.6 & -2.8 & 0.1 & 5.1 & -5.5 & 1.7 \\
STRG & 0.4 & -1.9 & -0.4 & 0.6 & -1.3 & -0.3 & 3.1 & -1.4 & 0.8 \\
POZN & 1.4 & -4.1 & 0.1 & 3.2 & -5.1 & 0.0 & 9.2 & -5.1 & 4.6 \\
WROC & 9.4 & -11.7 & 0.1 & $\mathbf{2 1 . 5}$ & $\mathbf{- 2 8 . 3}$ & 0.0 & 29.6 & -14.8 & 3.3 \\
\hline
\end{tabular}

The maximum range of differences in the North component for station SOCH (from 22.6 to $-5.9 \mathrm{~mm}$ ), in the East component for station WROC (from 21.5 to $-28.3 \mathrm{~mm}$ ) and in the Up component for station $\mathrm{SOCH}$ (from 30.6 to $-18.6 \mathrm{~mm}$ ) were obtained respectively.

By analyzing average differences obtained for the same antenna type, it is visible that the size of the obtained variations differs, which may be related to the size of the imperfections for a particular antenna/radome model. It was also observed that for two stations with LEIAR20 LEIM antenna (KOSC, STRG), where the biggest PCO differences occurred, the average North, East, Up differences are rather small in comparison to other station. This may suggest that PCO values are not the dominant factor causing the observed differences.

The effect of the variance of differences for SOCH and WROC stations is also visible in Table 6, where standard deviation is presented. For these two stations, as well as for LODZ station, the highest values were clearly obtained.

Table 6 Standard deviation of the obtained NEU differences for sub-daily results.

\begin{tabular}{crrr}
\hline \multirow{2}{*}{ POINT } & \multicolumn{3}{c}{ Standard deviation of differences $[\mathrm{mm}]$} \\
\cline { 2 - 4 } & North & \multicolumn{1}{c}{ East } & Up \\
\hline LODZ & $\mathbf{1 . 2}$ & $\mathbf{2 . 5}$ & $\mathbf{3 . 1}$ \\
USDL & 0.8 & 0.8 & 2.2 \\
KATO & 0.7 & 1.1 & 2.7 \\
SOCH & $\mathbf{1 . 5}$ & $\mathbf{2 . 1}$ & $\mathbf{3 . 9}$ \\
KOSC & 0.4 & 0.5 & 1.6 \\
STRG & 0.2 & 0.4 & 1.1 \\
POZN & 0.5 & 0.6 & 1.2 \\
WROC & $\mathbf{1 . 3}$ & $\mathbf{2 . 8}$ & $\mathbf{3 . 3}$ \\
\hline
\end{tabular}

A calculation of Lomb-Scargle spectrum for the data was performed (Scargle 1982, Townsend 2010). This type of periodogram is used for frequency/period analysis of data that is not collected at a regular time interval nor has missing data. As it is known, such situation occurs quite often in GNSS permanent observations. Figure 5 presents the results concerning the power of detected periodic signals in cycles per day (cpd), for all stations.

Considering the fact that if the power of LombScargle spectrum is bigger than 20-30, the periodicity is definitely real and strong periodic signals can be identified (Table 7).

The obtained results confirm the earlier observation that variations in differences in all stations have periods close to 8 hours. This is true for all stations and all position components. The only exception is POZN Up, where periodic signals are identified at $2.00 \mathrm{cpd}$ frequency. However, it is visible in Figure 6 that there is also some periodicity (power about 10) at 3 cpd frequency.

To prove the periodic signals related to the satellite geometry, calculation of Lomb-Scargle spectrum for the geometric dilution of precision (GDOP) data was performed (Fig. 6). Because the antenna PCVs are azimuth and elevation dependent, the differences between solutions with absolute and type mean PCO and PCV should result with periodic position differences related to the satellite geometry change. However, it is possible that with full GLONASS constellation the DOP coefficients will not show the satellite geometry changes - the effect will be averaged. For this reason the calculation of mean differences of PCC (dPCC) in all measurements epoch were also performed and analyzed using LombScargle periodogram. The mean dPCC, calculated using all available satellites in each single epoch, are also satellite geometry dependent but less sensitive to averaging. These calculations were performed for L1 frequency phase center corrections (L1 dPCC) as well as for iono-free linear combination phase center corrections (L3 dPCC) and presented in Figure 6.

Figure 6 presents the results concerning the power of detected periodic signals in cycles per day (cpd), for all analyzed stations. As was suspected, there was no periodicity found for the GDOP coefficient, which generally was very stable for all stations and reached value from 2 to 3 . In full GLONASS constellation the effect of satellite geometry in DOP coefficients is averaged and is not visible. 

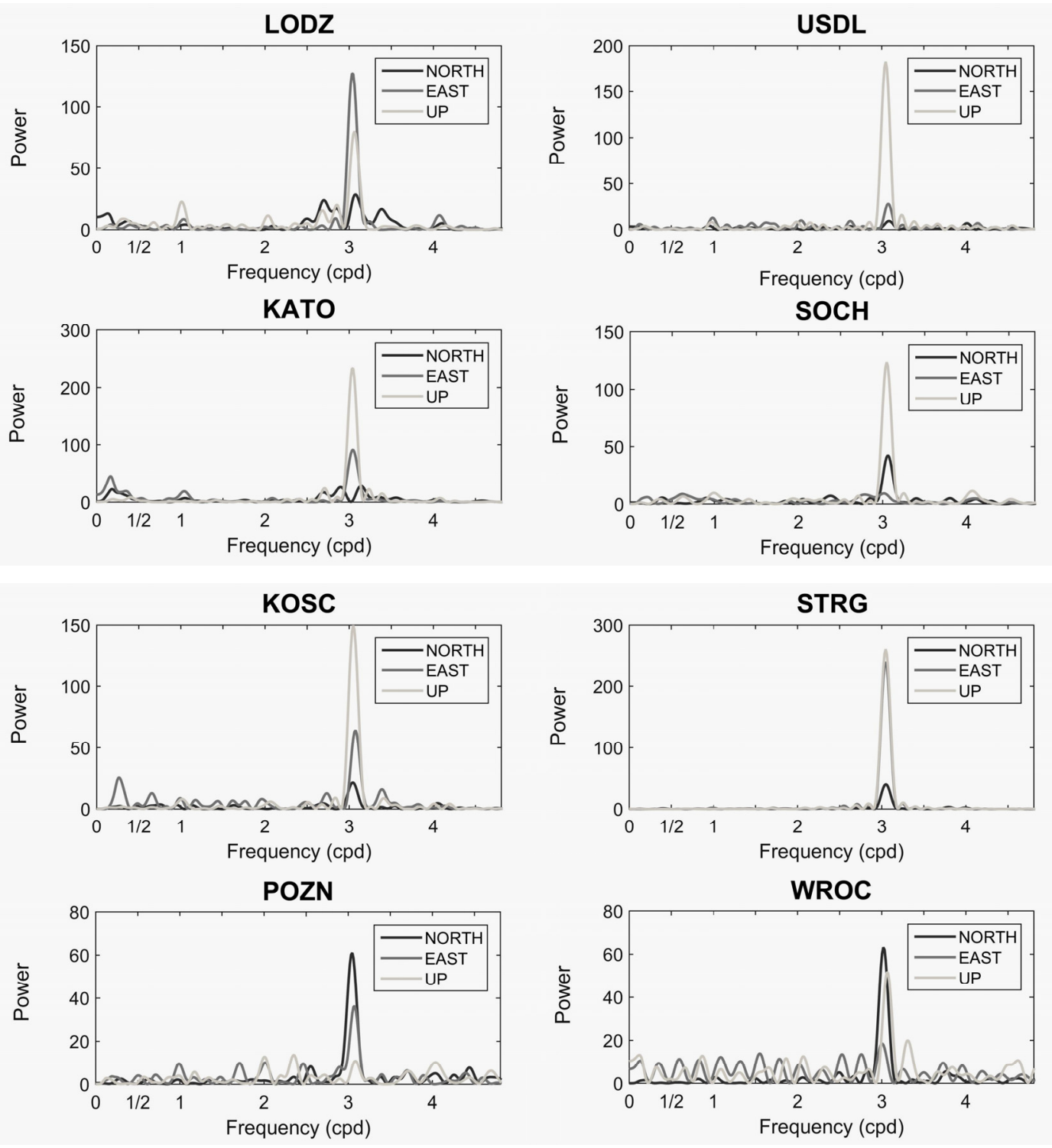

Fig. 5 Lomb-Scargle periodograms for sub-daily results.

Table 7 The strongest periodic signals identified in station position components in sub-daily results.

\begin{tabular}{lrrrrrr}
\hline Station & \multicolumn{2}{c}{ North } & \multicolumn{3}{c}{ East } & \multicolumn{2}{c}{ Up } \\
\cline { 2 - 6 } & cpd & power & cpd & power & cpd & power \\
\hline LODZ & 3.07 & 28.72 & 3.03 & 127.57 & 3.06 & 80.21 \\
USDL & 3.08 & 9.49 & 3.07 & 28.21 & 3.04 & 182.78 \\
KATO & 3.12 & 27.74 & 3.04 & 91.30 & 3.03 & 233.28 \\
SOCH & 3.06 & 42.40 & 3.01 & 9.14 & 3.04 & 123.52 \\
KOSC & 3.03 & 21.54 & 3.07 & 64.23 & 3.04 & 149.76 \\
STRG & 3.04 & 40.28 & 3.04 & 240.59 & 3.04 & 261.62 \\
POZN & 3.03 & 61.12 & 3.07 & 36.37 & $\mathbf{2 . 0 0}$ & $\mathbf{1 3 . 6 2}$ \\
WROC & 3.00 & 63.22 & 3.00 & 18.59 & 3.05 & 51.85 \\
\hline
\end{tabular}

On the other hand there was found strong periodicity for L1 and L3 mean dPCC data. Generally the discovered frequency equals $3,6,9$ and $12 \mathrm{cpd}$. These results prove that periodicity visible in the differences in all three position component are GLONASS constellation dependent.
Additional analysis of satellite visibility diagrams show that the satellite constellation above the measured points indeed was changed. There were some periods when almost all satellites at medium elevations were observed and periods when satellites were observed on low and high elevations only. 

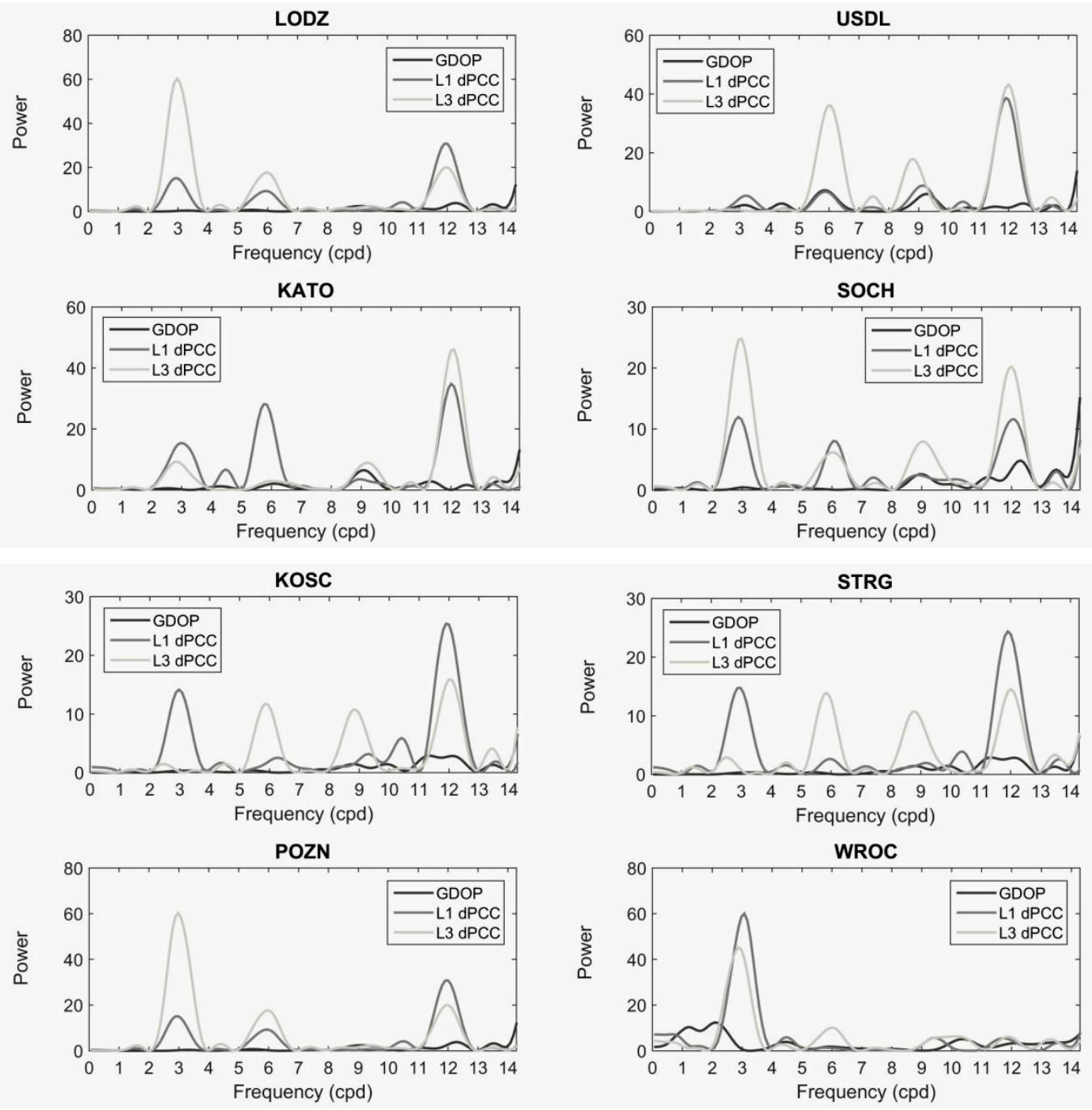

Fig. 6 Lomb-Scargle periodograms for GDOP, L1 mean dPCC and L3 mean dPCC data.

\section{DAILY RESULT ANALYSIS}

Each daily RINEX data set was also postprocessed once using the igs 08 .atx model and once using the individual calibration models. Results North, East and Up differences are presented in Figure 7.

By analyzing results presented in Figure 7, it is visible that for the horizontal components the position offsets induced by the differences between both individual calibrations are below $1 \mathrm{~mm}$. For most stations, the periods where some jumps occurred can be observed. This is visible especially for LODZ, KOSC and WROC where the observed changes achieve the greatest value.

The bigger differences can be seen for the Up component. These differences range from -3 to $5 \mathrm{~mm}$ depending on a station. It was found that for points with the same type of antenna the difference also significantly differs, e.g. LODZ and USDL stations or KATO and SOCH stations. These differences in results may be caused by differences visible in typemean and individual PCC. However, they also may be caused by the impact of so-called near-field effect, which can vary for different antenna localization.
Generally, this indicates that all antennas of the same type cannot necessarily be represented confidently by a unique type-mean calibration.

For UP component clear changes in time series differences are visible for almost all stations. However, it is difficult to identify the period of their occurrence.

Similarly as for sub-daily results there are also sites (e.g. POZN, WROC) where some outliers occurred. As previously, detailed analysis show that, during the period of these incidental residuals, some gaps in data occurred. Analyzing WROC station we found that on some days where such incidental residuals occurred, almost half of the observations were missing (due to gaps or observation rejections during post-processing). In this case also, all the outliers were removed during periodicity analysis using Lomb-Scargle periodogram.

Table 8 presents a summary of North, East, Up differences caused by the use of different calibration models in post-processing, i.e. maximum, minimum and average value of the obtained difference for all stations. 

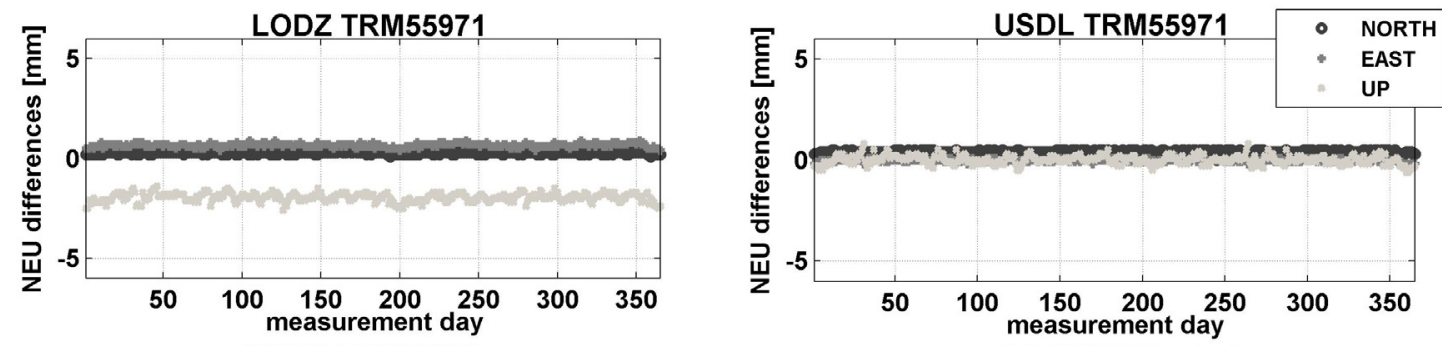

KATO TRM5797
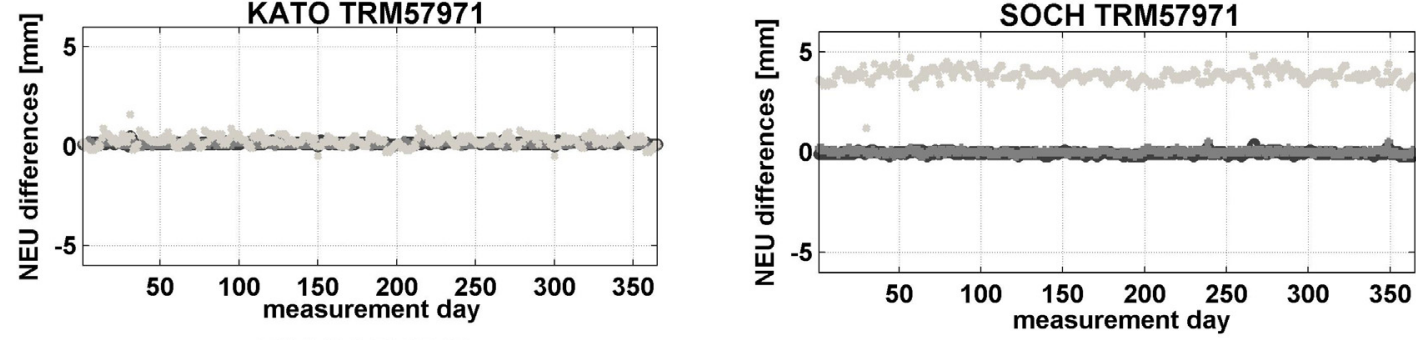

KOSC LEIAR20
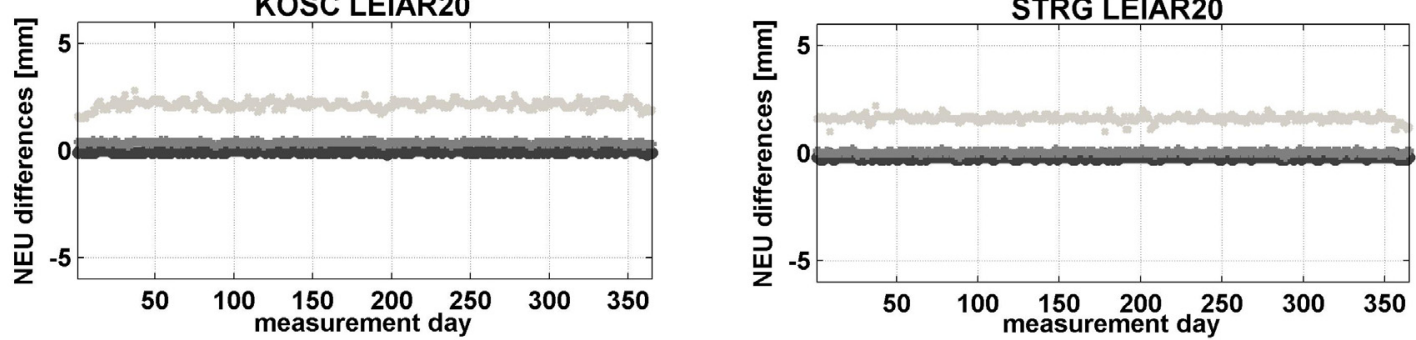

POZN TRM59900
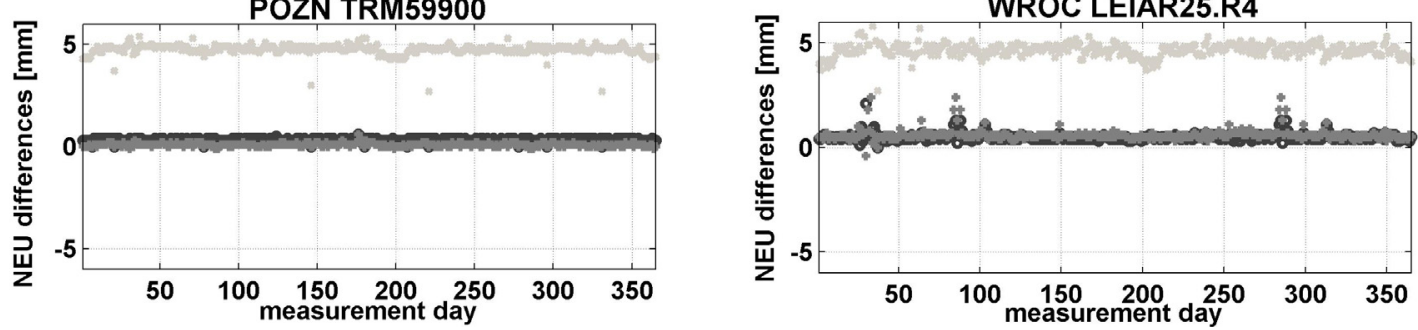

Fig. 7 North, East, Up differences caused by the use of different calibration models in postprocessing (from 1 December 2013 till 30 November 2014).

Table 8 Summary of North, East, Up differences.

\begin{tabular}{cccccccccc}
\hline POINT & \multicolumn{3}{c}{$\begin{array}{c}\text { North component } \\
\text { differences }[\mathrm{mm}]\end{array}$} & \multicolumn{3}{c}{ East component differences } & \multicolumn{2}{c}{$\begin{array}{c}\text { Up component differences } \\
{[\mathrm{mm}]}\end{array}$} \\
\cline { 2 - 10 } & Max. & \multicolumn{1}{c}{ Min. } & Average & Max. & Min. & Average & Max. & Min. & Average \\
\hline LODZ & 0.6 & 0.1 & 0.3 & 0.9 & 0.4 & 0.7 & -1.4 & -2.6 & -2.0 \\
USDL & 0.5 & 0.0 & 0.4 & 0.2 & -0.3 & 0.0 & 0.8 & -0.6 & 0.0 \\
KATO & 0.5 & 0.0 & 0.2 & 0.3 & -0.1 & 0.1 & 1.6 & -0.5 & 0.3 \\
SOCH & 0.4 & -0.2 & -0.1 & 0.5 & -0.2 & 0.0 & 4.8 & 1.2 & 3.8 \\
KOSC & 0.1 & -0.2 & 0.0 & 0.5 & 0.2 & 0.4 & 2.8 & 1.5 & 2.1 \\
STRG & 0.0 & -0.3 & -0.2 & 0.2 & -0.2 & 0.0 & 2.2 & 1.0 & 1.6 \\
POZN & 0.6 & 0.0 & 0.3 & 0.6 & -0.1 & 0.1 & 5.4 & 2.7 & 4.7 \\
WROC & $\mathbf{2 . 1}$ & $\mathbf{0 . 0}$ & 0.5 & $\mathbf{2 . 4}$ & $\mathbf{- 0 . 4}$ & 0.6 & $\mathbf{1 0 . 8}$ & $\mathbf{2 . 7}$ & 4.7 \\
\hline
\end{tabular}

Changing the calibration models in the postprocessing from type-mean to individual affects mostly the Up component. Generally, the estimated position offsets range from -0.3 to $0.6 \mathrm{~mm}$ in the North, from -0.4 to $0.9 \mathrm{~mm}$ in the East and -2.6 to $5.4 \mathrm{~mm}$ in the Up components. For WROC station, the maximum difference exceeds $2 \mathrm{~mm}$ in horizontal components and $10 \mathrm{~mm}$ in Up component. The effect of variance in differences for WROC stations is also visible in Table 9 where standard deviation is presented. The variance in WROC station results can be caused by the impact of near-field effect, which can be significant for this antenna localization. It can be also antenna type dependent. 
Table 9 Standard deviation of the obtained NEU differences.

\begin{tabular}{cccc}
\hline & POINT & & \multicolumn{2}{c}{ Standard deviation of differences [mm] } \\
\hline & North & East & Up \\
\hline LODZ & 0.1 & 0.1 & 0.2 \\
USDL & 0.1 & 0.1 & 0.2 \\
KATO & 0.1 & 0.1 & 0.3 \\
SOCH & 0.1 & 0.1 & 0.3 \\
KOSC & 0.1 & 0.1 & 0.2 \\
STRG & 0.1 & 0.1 & 0.2 \\
POZN & 0.1 & 0.1 & 0.3 \\
WROC & $\mathbf{0 . 2}$ & $\mathbf{0 . 3}$ & $\mathbf{0 . 6}$ \\
\hline
\end{tabular}
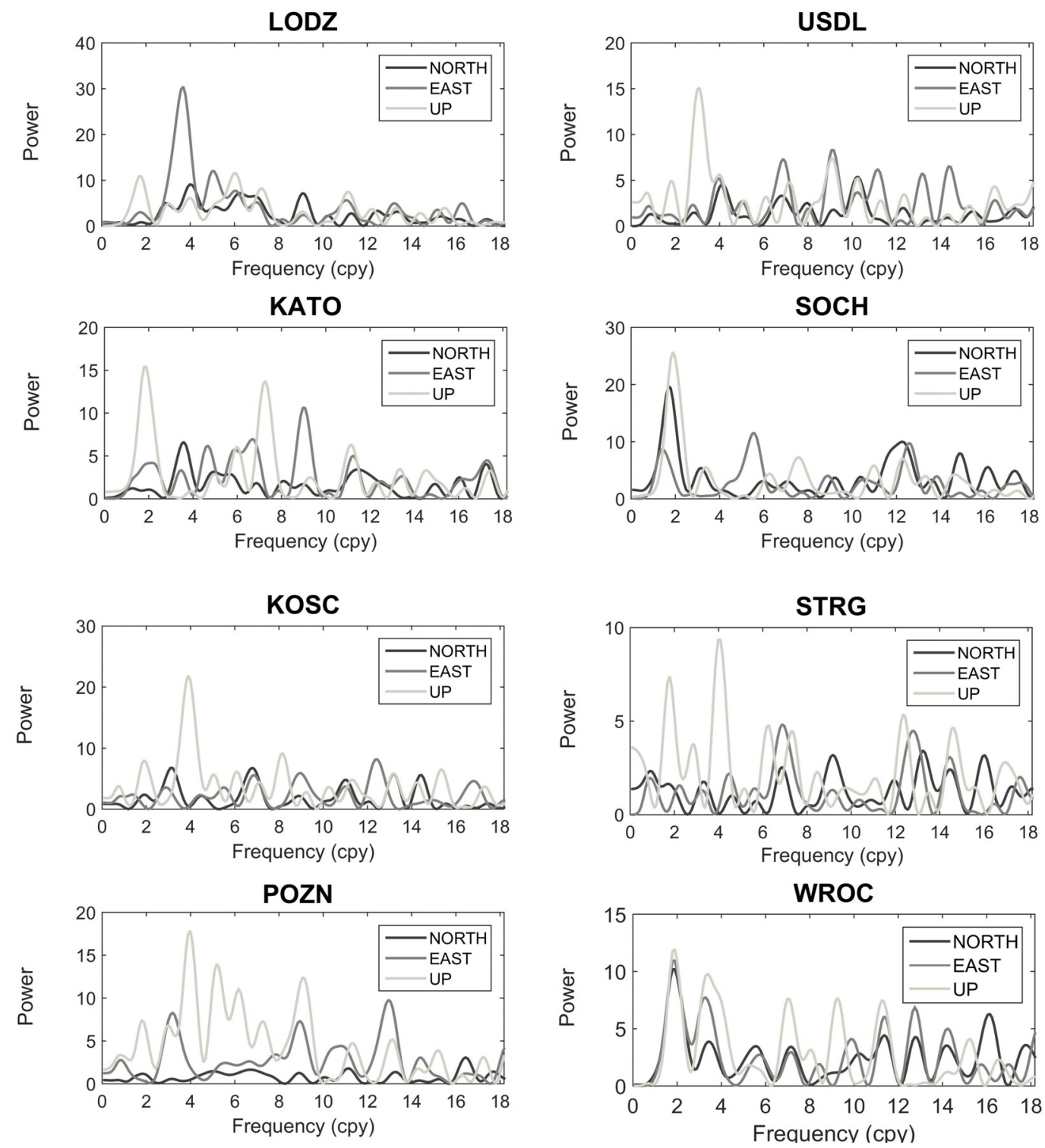

Fig. 8 Lomb-Scargle periodogram for daily results.

It was also observed, as in the sub-daily results, that for KOSC and STRG stations (the biggest PCO differences), the average North, East, Up differences are rather small in comparison to other station.

A calculation of Lomb-Scargle spectrum for daily time series differences was also performed.
Figure 8 presents the results concerning the power of detected periodic signals in cycles per year (cpy).

Considering the good "rule of thumb" for interpreting Lomb-Scargle power, i.e.:

power $<6$ - most likely not real,

$6<$ power $<10$ - may be real but probably not, 
Table 10 The strongest periodic signals identified in station position components in daily results.

\begin{tabular}{crrrrrr}
\hline Station & \multicolumn{2}{c}{ North } & \multicolumn{2}{c}{ East } & \multicolumn{2}{c}{ Up } \\
\cline { 2 - 7 } & cpw & power & cpw & power & cpw & power \\
\hline LODZ & 4.0 & 9.11 & $\mathbf{3 . 7}$ & $\mathbf{3 0 . 4 4}$ & 6.0 & 11.55 \\
USDL & 10.3 & 5.38 & 9.1 & 8.31 & $\mathbf{3 . 1}$ & $\mathbf{1 5 . 0 9}$ \\
KATO & 3.6 & 6.63 & 9.0 & 10.62 & $\mathbf{1 . 8}$ & $\mathbf{1 5 . 4 2}$ \\
SOCH & $\mathbf{1 . 7}$ & $\mathbf{1 9 . 7 2}$ & 5.6 & 11.52 & $\mathbf{1 . 9}$ & $\mathbf{2 5 . 6 7}$ \\
KOSC & 3.2 & 6.77 & 12.5 & 8.17 & $\mathbf{3 . 9}$ & $\mathbf{2 1 . 8 5}$ \\
STRG & 13.3 & 3.43 & 6.7 & 4.83 & 4.0 & 9.36 \\
POZN & 16.5 & 3.08 & 13.0 & 9.78 & $\mathbf{4 . 1}$ & $\mathbf{1 7 . 8 5}$ \\
WROC & 1.9 & 10.21 & 1.9 & 10.96 & 1.9 & 11.95 \\
\hline
\end{tabular}

$10<$ power $<14-$ might be real, worth investigating more,

$14<$ power $<20$ - most likely real, power $>20-30$ - definitely real,

it is visible (Table 10) that some "weak" periodicity is found there.

Considering only the frequencies where power exceeds 14 , one can observe the periodic signals at frequencies about 2, 3 and 4 cpy. Similar results were observed in Sidorov and Teferle (2013) where GPSonly observations were analyzed.

\section{CONCLUSIONS}

In the paper, the authors compared station positions estimated with type-mean and individual antenna calibration models. Position offsets were derived using eight selected ASG-EUPOS stations data set from December 2013 to November 2014, where five different antenna types were mounted. The influence of switching between these models was investigated using GLONASS-only observations. Post-processing was done using PPP technique in daily observation mode and in pseudo-kinematic mode (15 minutes session).

The analysis of the differences between typemean and individual PCC for chosen stations were performed. Generally, differences between type-mean and individual calibration tables for all antennas were observed. These differences can be treated as inaccuracies in type-mean PCC. The authors analyzed how these differences influence the position time series.

In pseudo-kinematic mode, one can see rapid changes of the obtained North, East and Up differences within short time periods, which is close to 8 hours. The three cycles per day period may be associated with three orbital planes in GLONASS.

The authors also observed that the position offsets in the height component are plainly bigger than for horizontal components and for some stations, they reach up to $10 \mathrm{~mm}$.

In average differences the authors observed that the size of the obtained variations for the same antenna type differ, which may be related to the size of imperfections for a particular antenna/radome model.

In pseudo-kinematic results, strong periodic signals were identified using Lomb-Scargle spectrum. The obtained results confirm earlier observation that variations in differences in all stations have periods close to 8 hours.

By analyzing daily results, it was visible that for the horizontal components the position offsets induced by the differences between both individual calibrations are below $1 \mathrm{~mm}$. For Up component the differences range from -3 to $5 \mathrm{~mm}$ depending on station. It was found that for points with the same type of antenna the difference also significantly differ. These differences in results may be caused by differences visible in type-mean and individual PCC. This could mean that not all the antennas of the same type can necessarily be represented confidently by a unique type-mean calibration. However, the differences may be also caused by the impact of the so-called near-field effect which can be different for different antenna localization. This issue requires further study.

The calculated Lomb-Scargle spectrum revealed that there is some "weak" periodicity. Considering only the frequencies where power exceeds 14, one can notice that the periodic signals at frequencies are about 2, 3 and 4 cpy.

To find all origins of the discovered periodicities further analysis is needed. Such analysis will require greater number of points and longer periods of observation.

\section{REFERENCES}

Baire, Q., Pottiaux, E., Bruyninx, C., Defraigne, P., Legrand, J. and Bergoet, N.: 2011, Comparison of receiver antenna calibration Models used in the EPN, http://www.euref.eu/symposia/2011Chisinau/Symposi um2011-Chisinau.html.

Baire, Q., Bruyninx, C., Legrand, J., Pottiaux, E., Aerts, W., Defraigne, P., Bergeot, N. and Chevalier, J.M.: 2013, Influence of different GPS receiver antenna calibration models on geodetic positioning. GPS Solution, 18, No. 4, 529-539. DOI: $10.1007 / \mathrm{s} 10291-013-0349-1$ 
Blewitt, G.: 2003, Self-consistency in reference frames, geocenter definition, and surface loading of the solid Earth. Journal of Geophysical Research, 108, No. B2(2103), 10. DOI: 10.1029/2002JB002082

Boehm, J., Niell, A.E., Tregoning, P. and Schuh, H.: 2006, The Global Mapping Function (GMF): A new empirical mapping function based on data from numerical weather model data. Geophysical Research Letters, 33, L07304. DOI: 10.1029/2005GL025546

Boehm, J., Heinkelmann, R. and Schuh, H.: 2007, Short Note: A global model of pressure and temperature for geodetic applications. Journal of Geodesy, 81, No. 10, 679-683. DOI: 10.1007/s00190-007-0135-3

Bosy, J., Oruba, A., Graszka, W., Leończyk, M. and Ryczywolski, M.: 2008, ASG-EUPOS densification of EUREF Permanent Network on the territory of Poland. Reports on Geodesy, 2, No. 85, 105-112.

Bogusz. J., Figurski,.M., Kroszczyński, K. and Szafranek, K.: 2011, Investigation of environmental influences to the Precise GNSS Solutions. Acta Geodyn. Geomater., 8, No. 1 (161), 5-15.

Bruyninx, C., Habrich, H., Söhne, W., Kenyeres, A., Stangl, G. and Völksen, C.: 2012, Enhancement of the EUREF Permanent Network Services and Products. Geodesy for Planet Earth, IAG Symposia Series, 136, $27-35$.

Chatazinikos, M., Fotiou, A. and Pikradis, C.: 2009, The effects of the receiver and satellite antenna phase center models on local and regional GPS networks. Proceedings of the International Symposium "Modern technologies, educations and professional practice in geodesy and relative fields", Sofia, 5-6 November.

Dawidowicz, K.: 2013, Impact of different GNSS antenna calibration models on height determination in the ASG-EUPOS network: a case study. Survey Review, 45, No. 332, 386-394. DOI: $10.1179 / 1752270613$ Y.0000000043

Dawidowicz, K., Kaźmierczak, R. and Świątek, K.: 2015, Short static GPS/GLONASS observation processing in the context of antenna chase center variations problem. Boletim de Ciências Geodésicas, 21, No. 1, 213-232. DOI: 10.1590/S1982-217020150001000014

El-Mowafy, A.: 2009, Alternative postprocessing relative positioning approach based on Precise Point Positioning. Journal of Surveying Engineering, 135, No. 2, 56-65. DOI: 10.1061/(ASCE)0733-9453(2009)135:2(56)

Figurski, M.., Kamiński., P., Kroszczyński., K. and Szafranek, K..: 2009, ASG-EUPOS monitoring with reference to EPN. Artificial Satellites, 44, 85-94. DOI: $10.2478 / \mathrm{v} 10018-009-0022-7$

Figurski, M.., Bogusz, J., Szafranek, K. and Kamiński., P.: 2010, Investigation on stability of mountainous EUPOS sites' coordinates. Acta Geodyn. Geomater., 7, No. 3, 263-274.

Geng, J., Meng, X., Teferle, F.N. and Dodson, A.H.: 2010, Performance of precise point positioning with ambiguity resolution for 1- to 4-hour observation periods. Survey Review, 42, No. 316, 155-165. DOI: $10.1179 / 003962610 X 12572516251682$

Görres, B., Campbell, M., Becker, M. and Siemes, M.: 2006, Absolute calibration of GPS antennas: Laboratory results and comparison with field and robot techniques. GPS Solutions, 10, 136-145. DOI: $10.1007 / \mathrm{s} 10291-005-0015-3$
Grinter, T. and Roberts, C.: 2011, Precise Point Positioning: Where are we now? Proc. IGNSS2011, Sydney, Australia, 15-17 November, 15 pp.

Kadaj, R.: 2010, Application of Schreiber's type difference observation system for elaboration of a session of static GPS measurements. Biuletyn Wojskowej Akademi Technicznej, LIX, No. 2(658), 85-106.

Kersten, T. and Schön, S.: 2014, Comparing antenna phase center corrections: challlenges, concepts and perspectives. IGS Workshop, June 23-27, Pasadena, California, USA

Khoda, O. and Bruyninx, C.: 2007, Switching from relative to absolute antenna phase center variations in a regional network: stability of the coordinate differences, Submitted to Proceedings of the Symposium of the IAG Subcommission for Europe (EUREF) held in London, England, 6-9 June 2007.

Kouba, J. and Héroux, P.: 2001, Precise point positioning using IGS orbit and clock products. GPS Solutions, 5, No. 2, 12-28. DOI: 10.1007/PL00012883

Leick, A., Rapoport, L. and Tatarnikov, D.: 2015, GPS Satellite Surveying, $4^{\text {th }}$ Edition, Wiley, $840 \mathrm{pp}$.

Meindl, M.: 2011, Combined analysis of observations from different Global Navigation Satellite Systems. PhD thesis, Technische Hochschule Zürich, http://www.sgc.ethz.ch/sgc-volumes/sgk-83.pdf.

Menge, F., Seeber, G., Völksen, Ch., Wübbena, G. and Schmitz, M.: 1998, Results of absolute field calibration of GPS antenna PCV. ION GPS-98; Proceedings of the 11th International Technical Meeting of the Satellite Division of the Institute of Navigation, Nashville, TN, USA, 15-18 Sept., 31-38.

Rebischung, P., Griffiths, J., Ray, J., Schmid, R., Collilieux, X. and Garayt, B.: 2011, IGS08: the IGS realization of ITRF2008. GPS Solution, 16, No. 4, 483-494. DOI: 10.1007/s10291-011-0248-2

Rizos, Ch., Janssen, V., Roberts, C. and Grinter, T.: 2012, Precise Point Positioning: Is the era of differential GNSS positioning drawing to an end? FIG Working Week 2012 Knowing to manage the territory, protect the environment, evaluate the cultural heritage, Rome, Italy, 6-10 May.

Rothacher, M.: 2001, Comparison of absolute and relative antenna phase center variations. GPS Solutions, 4, 5560. DOI: 10.1007 / PL00012867

Saastamoinen, J.: 1972, Atmospheric correction for the troposphere and stratosphere in radio ranging of satellites. In The Use of Artificial Satellites for Geodesy, Geophysical Monography Series, 15, Amer. Geophys. Union, 274-251. DOI: $10.1029 / \mathrm{GM} 015 \mathrm{p} 0247$

Scargle, J.D.: 1982, Studies in astronomical time series analysis. Astophysical Journal, 263, 835-853. DOI: $10.1086 / 160554$

Scherneck, H.-G.: 1991, A parameterized Solid Earth Tide Model and Ocean Tide Loading Effects for global geodetic baseline measurements. Geophysical Journal International, 106, No. 3, 677-694. DOI: $10.1111 / \mathrm{j} .1365-246 X .1991 . t b 06339 . x$

Schupler, B.R. and Clark, T.A.: 2001, Characterizing the behavior of geodetic GPS antennas. GPSWorld, February, 48-55.

Schmid, R., Rothacher, M., Thaller, D. and Steigenberger, P.: 2005, Absolute phase center corrections of satellite and receiver antennas. GPS Solutions, 9, No. 4, 283293. DOI: $10.1007 / \mathrm{s} 10291-005-0134-\mathrm{x}$ 
Schmid, R.: 2011, Upcoming switch to IGS08/igs08.atx Details on igs08.atx. IGSMAIL-6355,

http://igscb.jpl.nasa.gov/pipermail/igsmail/2011/006347.html

Seeber, G. and Böder, V.: 2002, Entwicklung und Erprobung eines Verfahrens zur hochpräzisen Kalibrierung von GPS Antennenaufstellungen Schlussbericht zum BMBF/DLR Vorhaben 50NA9809/8. Institut für Erdmessung.

Seeber, G., Menge, F., Völksen, C., Wübbena, G., and Schmitz, M.: 1997, Precise positioning improvements by reducing antenna and site dependent effects. IAG Symposium in Rio de Janeiro, IUGG Assembly, Springer Verlag, 115.

Shen, X.: 2002, Improving ambiguity convergence in carrier phase based precise point positioning, UCGE Rep. No. 20170, Dept. of Geomatics Engineering, Univ. of Calgary, Canada.

Sidorov, D. and Teferle, F.N.: 2013, Antenna phase centre calibration effects on position time-series: Preliminary results. Presented in IAG Scientific Assembly, IAG 150 Years, Potsdam, Germany, September 1-6.

Springer, T. A.: 2009, Napeos - mathematical model and algorithms. European Space Agency (ESA), DOPS-SYS-TN-0100-OPS-GN(1):150.

Townsend, R. H. D.: 2010, Fast calculation of LombScargle periodogram using graphics processing units. The Astronomical Journal, 191, 247-253. DOI: $10.1088 / 0067-0049 / 191 / 2 / 247$

Völksen, Ch.: 2006, The impact of different GPS Antenna Calibration Models on the EUREF Permanent Network. Report on the Symposium of the IAG Subcommission for Europe (EUREF). Mitteilungen des BKG, Band 38, Verlag des BKG, Frankfurt/Main, 7378.
Wanninger, L.: 2011, Carrier-phase inter-frequency biases of GLONASS receivers. Journal of Geodesy, 86, No. 2, 139-148. DOI: 10.1007/s00190-011-0502-y

Wübbena, G., Menge, F., Schmitz, M., Seeber, G. and Völksen, Ch.: 1996, A new approach for field calibration of Absolute Antenna Phase Center variations. Presented at ION GPS-96, Kansas City, Missouri, September, 1205-1214.

Wübbena, G., Schmitz, M., Boettcher, G. and Schumann, Ch.: 2006, Absolute GNSS antenna calibration with a robot: Repeatability of phase variations. Calibration of GLONASS and determination of carrier-to-noise pattern. Submitted to the Proceedings of the IGS Workshop: Perspectives and Visions for 2010 and beyond, 8-12 May 2006, Darmstadt, Germany.

Zeimetz, P. and Kuhlman, H.: 2008: On the accuracy of absolute GNSS antenna calibration and the conception of a new anechoic chamber. FIG Working Week 2008, Stockholm, Sweden 14-19 June.

Zumberge, J.F., Hein, M.B., Jefferson, D.C., Watkins, M.M. and Webb, F.H.: 1997, Precise Point Positioning for the efficient and robust analysis of GPS data from large networks. Journal of Geophysical Research, 102(B3), 5005-5017. DOI: 10.1029/96JB03860 